\title{
Serial Intrauterine Transfusions for a Hydropic Fetus with Severe Anemia and Thrombocytopenia Caused by Parvovirus: Lessons Learned
}

\author{
Pedro S. Argoti, MD ${ }^{1}$ Michael Bebbington, MD ${ }^{1}$ Michael Adler, MD ${ }^{1} \quad$ Anthony Johnson, DO ${ }^{1}$ \\ Kenneth J. Moise, Jr., MD ${ }^{1}$ \\ ${ }^{1}$ Division of Maternal-Fetal Medicine, Department of Obstetrics, \\ Gynecology and Reproductive Medicine, University of Texas School of \\ Address for correspondence Pedro Argoti, MD, 6410 Fannin, Suite \\ 700, Houston, TX 77030 (e-mail: Pedro.Argoti@uth.tmc.edu).
} Medicine at Houston, The Texas Fetal Center, Children's Memorial

Hermann Hospital, Houston, Texas

Am J Perinatol Rep 2013;3:75-78.

\begin{abstract}
Keywords

- parvovirus

- intrauterine transfusion

- fetal thrombocytopenia

- platelet count

Introduction Fetal exsanguination is a rare complication of cordocentesis. Successful correction of fetal thrombocytopenia is essential for the reduction of risks.

Case Report A 25-year-old, gravida 3, P2-0-0-0-2, was referred at 27 weeks of gestation for evaluation of newly diagnosed nonimmune hydrops secondary to parvovirus infection. Despite the use of ancillary platelet transfusions to correct the severe fetal thrombocytopenia, prolonged bleeding from the cord puncture site still occurred, necessitating five intrauterine transfusions to ultimately correct the fetal anemia.

Conclusions The use of a smaller-diameter procedure needle, correction of the fetal thrombocytopenia early in the procedure, and external cord compression with the ultrasound transducer were ultimately successful measures in allowing for minimal loss of transfused red cells from the intravascular compartment.
\end{abstract}

Human parvovirus B19 seroprevalence and seroconversion rates vary according to age and geography. Seasonal variations have been observed. Among susceptible women during endemic and epidemic periods, the rate of seroconversion has been reported as 1.5 and $13.0 \%$, respectively. ${ }^{1}$ Although hydrops fetalis is a rare complication, it can rapidly lead to fetal demise. Intrauterine transfusion of red cells has been demonstrated to be an effective intervention with an improved fetal survival of $83.5 \%{ }^{2}$ Severe thrombocytopenia has been reported in approximately half of fetuses with hydrops undergoing intrauterine transfusion for parvovirus infection, although the mechanism is not clear. ${ }^{3}$ Severe thrombocytopenia can complicate intrauterine transfusion procedures with cases of fetal exsanguination following cordocentesis for other conditions such as alloimmune thrombocytopenia. ${ }^{4}$
Here we describe a case of severe thrombocytopenia complicating intrauterine transfusion for severe fetal anemia caused by parvovirus infection and the unique strategies employed to deal with this condition.

\section{Case Report}

A 25-year-old, gravida 3, P2-0-0-0-2, was referred at 27 weeks of gestation for evaluation of newly diagnosed nonimmune hydrops. A routine follow-up ultrasound at 26 weeks and 4 days of gestation revealed hydrops fetalis. A comprehensive review of her medical records and her history revealed only exposure at around 20 weeks of gestation to a neighbor's infant diagnosed with "fifth disease." The patient gave no history of febrile illness or rash. received

January 31, 2013 accepted after revision

February 6, 2013

published online

March 19, 2013
DOI http://dx.doi.org/

10.1055/s-0033-1341576. ISSN 2157-6998.
Copyright $\odot 2013$ by Thieme Medical Publishers, Inc., 333 Seventh Avenue, New York, NY 10001, USA. Tel: +1(212) 584-4662.
License terms

(요 (1) $\Theta \circledast$ 
INITLL ASSESSMENT :HYOROPS FELAUS
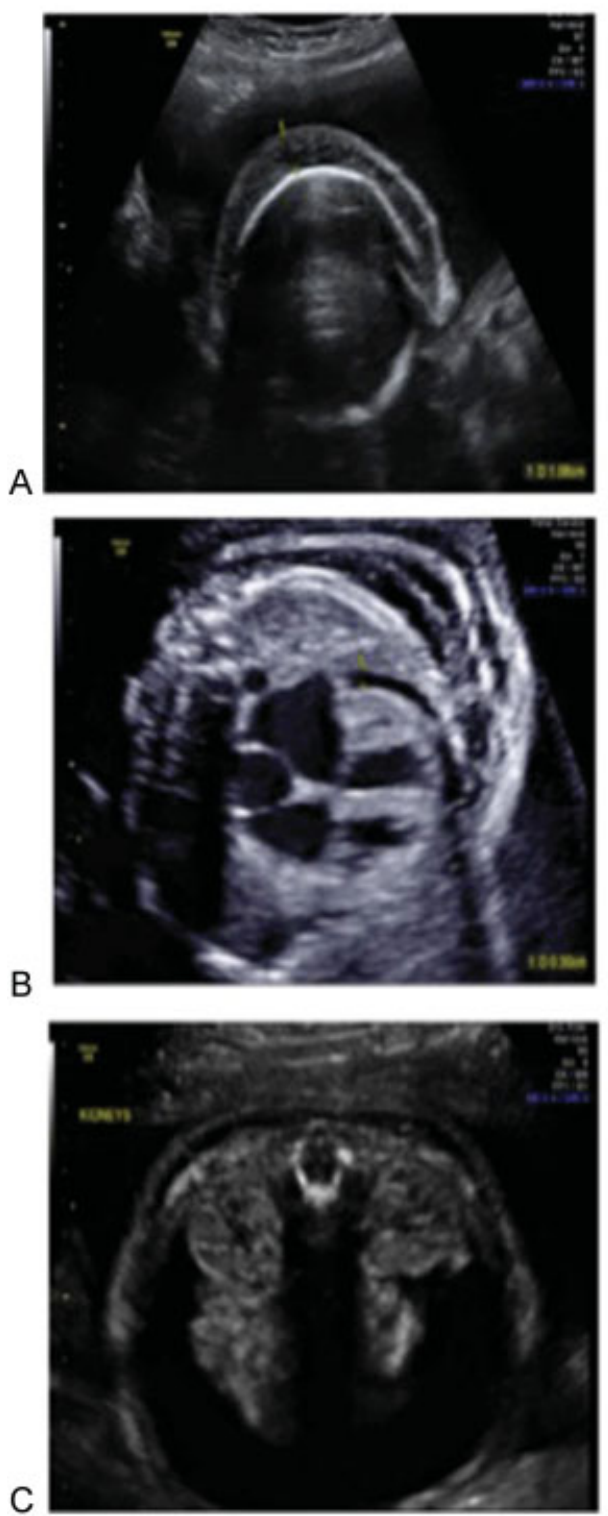

FOUR WEES AF TER LAST TRAHSFUSION HTDROPS RESOLIIOW
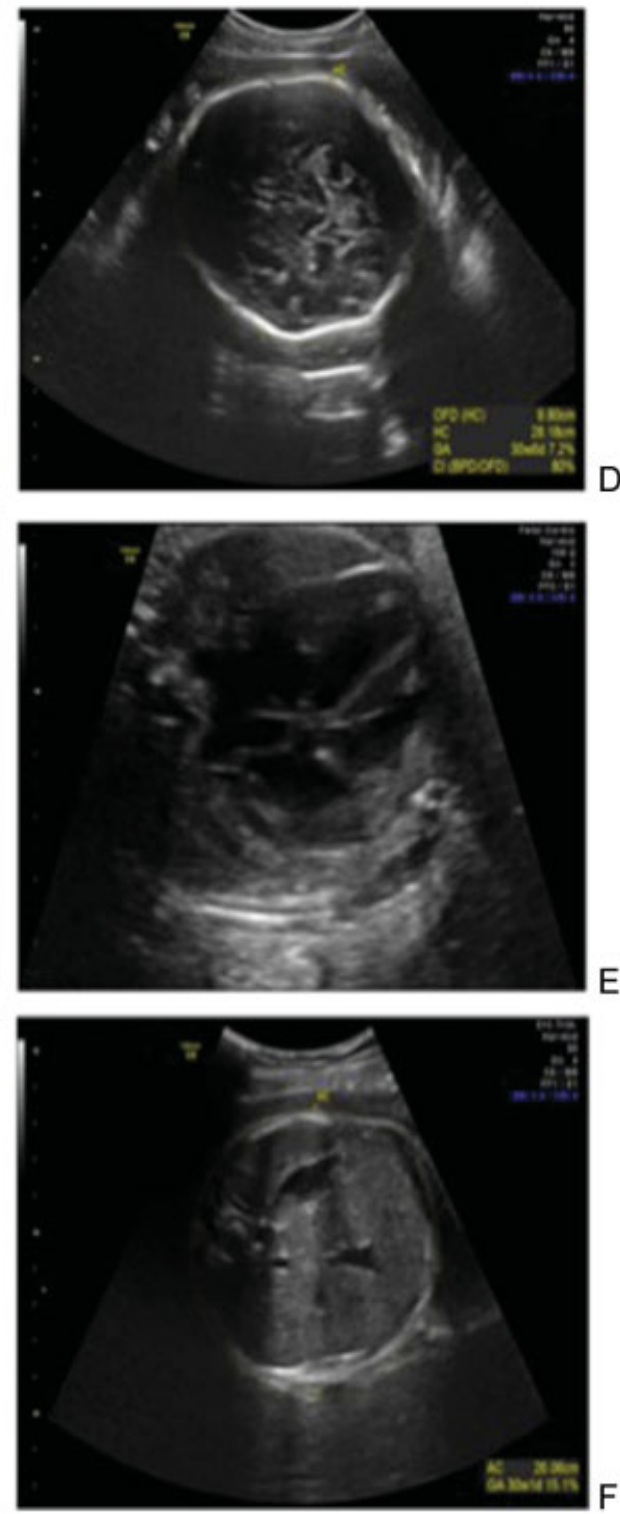

Fig. 1 Initial assessment: (A) Scalp edema, (B) pericardial effusion, (C) ascites. Resolution of hydrops $\sim 4$ weeks after last successful intrauterine transfusion: (D) resolution of scalp edema, (E) resolution of the pericardial effusion, (F) resolution of the ascites.

On initial assessment, a severely hydropic fetus was found with cardiomegaly complicated by severe mitral and tricuspid regurgitation as well as scalp edema, pericardial effusion, and significant ascites (see - Fig. 1A-C). Doppler examination of the middle cerebral artery revealed a peak systolic velocity of 3.06 multiples of median (MOM). A score of $2 / 8$ for the biophysical profile was found. The posterior placenta was hydropic. A maternal antibody screen was negative, the rapid plasma region (RPR) was nonreactive, and Kleihauer-Betke stain was negative for a fetomaternal hemorrhage. A maternal IgM assay for parvovirus drawn at the referring hospital later showed elevated levels. Given the suspected etiology and status of the fetus, an initial emergency intrauterine blood transfusion was planned.
At the initial transfusion, a 20-gauge procedure needle was used to puncture the fetal umbilical vein near the insertion of the cord into the placenta. Severe fetal anemia (hematocrit: $4.8 \%)$ and thrombocytopenia $\left(26 \times 10^{3} / \mu \mathrm{L}\right)$ was noted. The procedure was uncomplicated until dislodgement of the needle after a total of $40 \mathrm{~mL}$ of donor red cells (hematocrit: 77\%) had been transfused. Prolonged bleeding was noted from the puncture site; however, there were no changes in the fetal heart rate. Initial blood samples revealed a fetal blood type $O$ positive, negative direct Coombs test, and normal hemoglobin electrophoresis. Fetal karyotype by fluorescence in situ hybridization was normal. Fetal blood and amniotic fluid were positive for parvovirus B19 by polymerase chain reaction. 


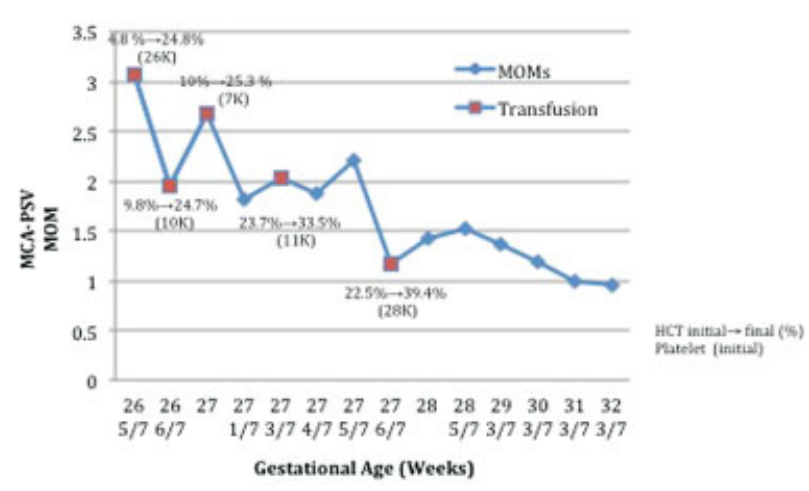

Fig. 2 Progression of the MCA-PSV pre- and posttransfusions. Values for pre- and posttransfusion fetal hematocrit and pretransfusion fetal platelet counts are also graphically represented. Abbreviations: HCT, hematocrit; MCA-PSV, middle cerebral artery peak systolic velocity; MOM, multiples of median.

Due to persistent elevation of the middle cerebral artery peak systolic velocity (MCA-PSV) at the time of the postoperative ultrasound 24 hours after each procedure, four additional intrauterine transfusions were required. For the second, third, and fourth procedures, platelets were infused after the initial fetal blood sample confirmed thrombocytopenia (-Fig. 2). Red cell transfusions were then undertaken in each case. Despite this effort, prolonged bleeding was noted from the cord puncture site at the time of removal of the procedure needle.

For the final procedure, a decision was made to attempt the cord puncture with a 22-gauge needle even though this would make the transfusion of the tightly packed red cells (hematocrit: 85\%) difficult. Upon withdrawal of the needle, there was some bleeding that responded to cord compression with the ultrasound transducer through the abdominal wall. Subsequent MCA-PSV Doppler measurements remained in the normal range consistent with retention of the last red blood cell transfusion and subsequent recovery of fetal erythropoiesis. Weekly serial ultrasounds revealed resolution of the fetal hydrops and normalization of the MCA-PSV (see - Fig. 1D-F).

The patient was induced at 37 weeks' gestation with delivery of a 2470-g male neonate with Apgar scores of 8 at 1 minute and 9 at 5 minutes. The cord hematocrit was noted to be $37.8 \%$ with a platelet count of $273 \times 10^{3} / \mu \mathrm{L}$.

\section{Discussion}

This case illustrates several important lessons. Fetal parvovirus infection is a known cause of fetal thrombocytopenia in addition to anemia. ${ }^{5}$ de Haan et al found that $47 \%$ of hydropic fetuses secondary to parvovirus infection had an initial fetal platelet count of $<50 \times 10^{3} / \mu \mathrm{L}^{3}$ In their series, all of these patients were transfused platelets in addition to red cells. In addition, all fetuses without initial thrombocytopenia demonstrated a significant decrease in their platelet count at the completion of the red cell transfusion. In $57 \%$ of cases, the final platelet count was $<50 \times 10^{3} / \mu \mathrm{L}$; however, platelet infusions were not administered. Using this protocol, no bleeding complications from the cord puncture site were noted to occur.

The addition of platelet transfusion to the red cell transfusion involves a significant increase in administered volume. The hydropic fetus infected with parvovirus is already in a state of cardiac compromise secondary to parvovirusinduced myocarditis and severe anemia. Therefore the risks of platelet transfusion must be weighed against the potential for significant postprocedural bleeding from the cord puncture site.

Despite these concerns, it would seem prudent to have platelets available at the time of the initial red cell transfusion in all hydropic fetuses with parvovirus. ${ }^{6}$ The standard formula for determining the amount of platelets to infuse is based on the calculated fetoplacental blood volume (FPV; estimated weight in grams $\times 0.14$ ).

The formula is then

FPV $\times($ target platelet count - initial platelet count $) \times 2$

Platelet count of the transfused concentrate (3).

A factor of 2 is included in the equation to account for acute sequestration of infused platelets in the fetal liver and spleen. Usually a target platelet count of 100 to $150 \times 10^{3} / \mu \mathrm{L}$ should be sufficient to prevent bleeding at the puncture site.

Our case also illustrates the importance of having an automated cell counter immediately available at the time of the planned intrauterine transfusion. This would allow the operator to plan for platelet transfusion based on the initial fetal platelet count early in the procedure to prevent bleeding from the puncture site should the needle become dislodged. We would therefore propose that an initial fetal blood sample be obtained for analysis and the red cell transfusion started. If the initial platelet count returns at $<50 \times 10^{3} / \mu \mathrm{L}$, the red cell transfusion should be stopped and the appropriate amount of platelets infused. Finally the red cell transfusion can be completed to attain a target hematocrit.

Past publications describing cordocentesis in fetuses at risk for thrombocytopenia have not made specific recommendations regarding optimal needle size. ${ }^{7}$ However, based on our experience, the use of a smaller-diameter needle (22-gauge versus the usual 20-gauge) should be considered when severe fetal thrombocytopenia is suspected. In rare cases where the puncture site is located at a superficial depth immediately below the ultrasound transducer, compression of the site through the maternal abdominal wall may be feasible and may aid in limiting the duration of the postpuncture bleeding.

Some experts advocate the use of the intrahepatic portion of the umbilical vein as a target for fetal vascular access. ${ }^{8}$ Potential advantages include a decreased incidence of fetal bradycardia and absorption of extravasated blood from the puncture site. Although in theory this latter advantage may have been beneficial in our case, we did not target the intrahepatic umbilical vein for two reasons. First, we were concerned about additional bleeding from the hepatic parenchyma itself due to the fetal thrombocytopenia. Second, any extravasated blood would likely 
remain in the peritoneal cavity because hydropic fetuses demonstrate poor absorption of red cells transfused intraperitoneally. ${ }^{9}$

\section{References}

1 Valeur-Jensen AK, Pedersen CB, Westergaard T, et al. Risk factors for parvovirus B19 infection in pregnancy. JAMA 1999;281: 1099-1105

2 Rodis JF, Borgida AF, Wilson M, et al. Management of parvovirus infection in pregnancy and outcomes of hydrops: a survey of members of the Society of Perinatal Obstetricians. Am J Obstet Gynecol 1998;179:985-988

3 de Haan TR, van den Akker ES, Porcelijn L, Oepkes D, Kroes AC, Walther FJ. Thrombocytopenia in hydropic fetuses with parvovirus B19 infection: incidence, treatment and correlation with fetal B19 viral load. BJOG 2008;115:76-81
4 Paidas MJ, Berkowitz RL, Lynch L, et al. Alloimmune thrombocytopenia: fetal and neonatal losses related to cordocentesis. Am J Obstet Gynecol 1995;172(2 Pt 1):475-479

5 Segata M, Chaoui R, Khalek N, Bahado-Singh R, Paidas MJ, Mari G. Fetal thrombocytopenia secondary to parvovirus infection. Am J Obstet Gynecol 2007;196:e1-e4

6 Kenneth J, Moise J. Intrauterine fetal transfusion of platelets. Uptodate. April 18, 2012. Available at: http://www.uptodate. com; Accessed November 13, 2012.

7 Berkowitz RL, Kolb EA, McFarland JG, et al. Parallel randomized trials of risk-based therapy for fetal alloimmune thrombocytopenia. Obstet Gynecol 2006;107:91-96

8 Nicolini U, Nicolaidis P, Fisk NM, Tannirandorn Y, Rodeck CH. Fetal blood sampling from the intrahepatic vein: analysis of safety and clinical experience with 214 procedures. Obstet Gynecol 1990; 76:47-53

9 Hashimoto B, Filly RA, Callen PW, Parer JT. Absorption of fetal intraperitoneal blood after intrauterine transfusion. J Ultrasound Med 1987;6:421-423 